\title{
Targeted water releases to flush fine sediment out of a bypassed reach of the Durance River downstream of four dams
}

\author{
Rémi Loire ${ }^{1,2}$, Hervé Piégay ${ }^{2}$, Jean-René Malavoi ${ }^{1}$, Leah Bêche ${ }^{1}$, Quentin Dumoutier ${ }^{3}$ and \\ Julie Mosseri ${ }^{4}$ \\ ${ }^{1}$ EDF, Hydro Engineering Center, Savoie Technolac, 73323, Le Bourget du Lac, France \\ ${ }^{2}$ University of Lyon, UMR5600 CNRS EVS, ENS Lyon, 15 Parvis R. Descartes, France \\ ${ }^{3}$ SAGE Environnement, 12 Ave du Pré de Challes, 74940, Annecy Le Vieux, France \\ ${ }^{4}$ EDF Mediterranean Production Unit, 10 Ave Vitton, 13482, Marseille Cedex 20, France
}

\begin{abstract}
The Durance River is a highly regulated, gravel-bed river with a naturally high fine sediment load in southern France. EDF operates eight dams along the regulated main stream channel (218 $\mathrm{km}$ from the Serre-Ponçon Dam to the confluence with the Rhône River), that divert water to 16 hydroelectric power plants via a canal. Flow regulation has contributed to fine sediment accumulation (clogging) in the Durance River. In addition to a recent increase in minimum flows has implemented targeted water releases at four out of eight dams to simulate floods and reduce clogging to restore river function for fishes and invertebrates, The timing of these releases is defined for each dam based on the spawning period of target fish species. During the release, TSS, O2, T, H, and conductivity are measured continuously. Before and after each release, clogging (superficial/interstitial) is measured. This monitoring program showed that several of the releases were not effective on surface clogging inducing a loss of water or resulted in effects contrary to those sought, although this was not reflected in the biological results. These results indicate that two parameters must be taken into account to determine a priori the need to carry out releases: the hydrology observed during the year and the initial level of clogging. Artificial flood releases are increasingly being used a management tool to mitigate hydropower impacts on river hydromorphology and ecology. This experimentation shows that it is necessary to carry out these types of operations in an adaptive management context. At this time, the results obtained do not lead to clear conclusions regarding their efficacy, mostly as a result of strong interannual variation in hydroclimatic conditions, which have a strong influence on initial conditions and resulting outcomes. Furthermore, it is important to incorporate this field measurements and not rely solely on turbidity gauging stations to evaluate efficacy.
\end{abstract}




\section{Introduction}

Large-scale flow experiments are becoming more common as an increasing focus on improving aquatic habitat quality and regulatory pressures incite dam operators to partially restore natural flow regimes [1]. Flow regime restoration can take many forms: establishing minimum environmental flows, reintroducing natural variability, releasing clear water, or combining a set of measures.

In France, we have developed a "morphogenic water release concept" which aims at optimally design the necessary flows/duration of these releases on the basis of "expected results" clearly defined by the stakeholder. The most common "expected results" range from simple surface cleaning of coarse alluvial substrates (low flow/duration releases) to active lateral erosion of meanders (high flow/duration releases) and removal of alluvial vegetation from the medium bed. One of these objectives may concern reducing fines elements accumulation in downstream reaches that occurs, as a result of reduced bedmobilizing flows and high sediment load from tributaries.

Mediterranean rivers are characterized by seasonal flow regime, with high flow in winter and spring, and low summer base-flows. In South-Eastern France, the Durance River, one of the biggest Rhône River tributary, has a highly altered flow regime resulting from extensive hydropower production and other water uses (e.g. irrigation). Eight dams are present on the Durance, creating several bypassed reaches, with most of the water flowing into canals parallel to the bypassed reach. With the exception of the most upstream large capacity dam, Serre-Ponçon, peak floods regularly exceed dam capacities and spill into the bypassed (i.e. minimum-flow) reaches.

Because of the naturally high fine sediment load in the Durance River (inputs from torrential tributaries draining badlands), unpredictable high flow events with dam overspill are not always sufficient to prevent clogging, which has led to habitat degradation in bypassed reaches. Therefore, in addition to a regulatory increase in minimum flows (as of January 2014), EDF is conducting a large-scale flow experiment, in the context of adaptive management, to test the efficiency of clear-water releases (close to the flushing flows concept) to restore benthic habitat conditions (by reducing clogging of gravel substrates) prior to spawning periods. Four reaches are targeted by these releases, downstream of the following dams: Espinasses, La Saulce, l'Escale and Cadarache (Figure 1).

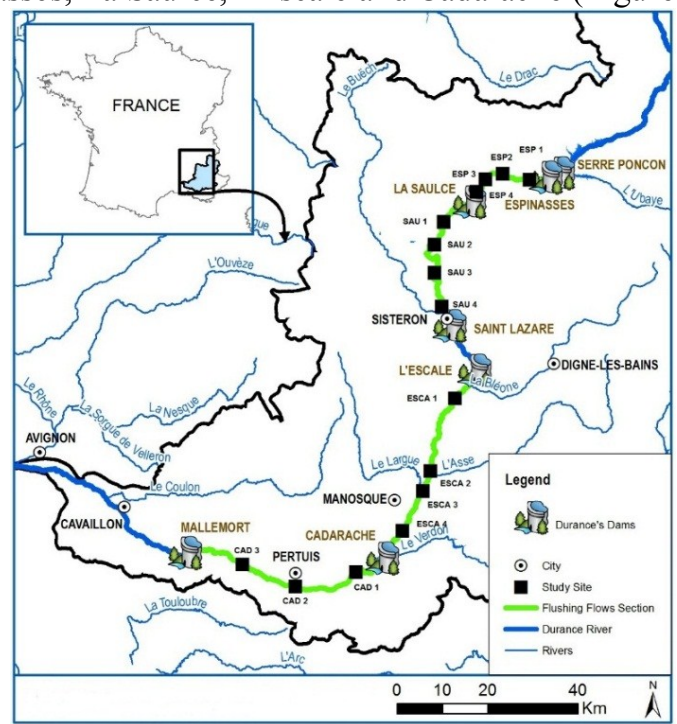

Fig. 1. The Durance River in France: reaches where clear-water releases are being experimented (flushing flows), dams and study sites. 


\section{Design of the water releases}

Previous experiments demonstrated that clogging (or surficial substrate fining) can reestablish very quickly right after clear-water releases; therefore, the target period for releases is as close as possible to the onset of spawning activity of each target fish species. Given the experimental nature of these mitigation measures, EDF was committed to conducting annual clear-water releases for an initial period of 3 years, after which their efficiency will be evaluated to adapt future flow management. A comprehensive long-term monitoring program has been therefore implemented (2014-2017). One release per year was scheduled for the four reaches. Of the 16 programmed releases in the period, only 12 were undertaken (Table 1). Four releases were cancelled because of the occurrence of two large flood events, a period with too high temperature and PCB pollution.

Table 1. Releases experimented during the monitoring program

\begin{tabular}{|c|c|c|c|c|}
\hline Reach & $\mathbf{2 0 1 4}$ & $\mathbf{2 0 1 5}$ & $\mathbf{2 0 1 6}$ & $\mathbf{2 0 1 7}$ \\
\hline Espinasses & $13-\mathrm{Nov}$ & 17-Nov & 15-Nov & $\begin{array}{c}\text { 14-Nov; not } \\
\text { yet analyzed }\end{array}$ \\
\hline La Saulce & $04-\mathrm{Feb}$ & $12-\mathrm{Feb}$ & 02-Feb & 31-Jan \\
\hline L'Escale & Cancelled & Cancelled & 16-Feb & 14-Feb \\
\hline Cadarache & Cancelled & Cancelled & 26-Apr & 25-Apr \\
\hline
\end{tabular}

The flow necessary to initiate fine sediment movement without resulting in generalised sediment transport (of larger particles) was estimated by expert opinion and the analysis of a few historic events. This flow value is expected to be adjusted according to monitoring results. Moreover, it was agreed that flow releases should not overflow some sensitive zones (namely agricultural fields and levees) and thewater level must also rise progressively for safety security reasons. Flow releases was then calculated to ensure that fine sediments can be entirely entrained to the downstream reach.
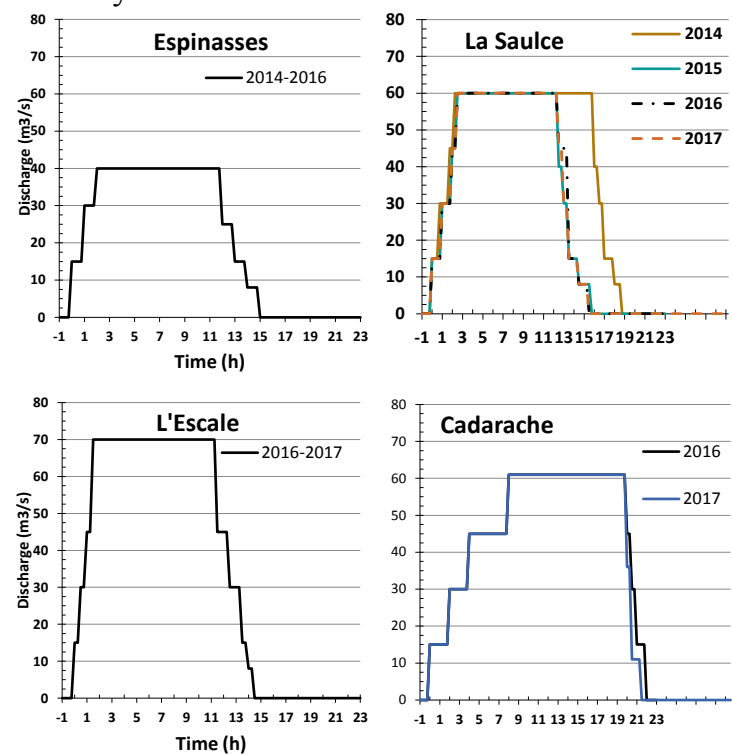

Fig. 2. Hydrographs of the clear-water releases run in each reach for the years 2014-2017 
The duration of the hydrographs varies between 15 and 21 hours to ensure the transit of the suspended sediment (SSC) through the entire reach (Figure 2). The flows range from 40 to $70 \mathrm{~m}^{3} \mathrm{~s}-1$. The ascent to the peak flow is progressive and lasts between $1 \mathrm{~h}$ and $2 \mathrm{~h} 30$ except at Cadarache, where the ascent is slower for safety reasons. The falling phase lasts between 2 and 3 hours. Whatever the year and the reach, the hydrographs are fairly similar, with the exception of La Saulce in 2014, which was extended to manage water levels in the lateral canal..

\section{Hydrological context}

At the Espinasses reach, no dam overspills were observed except those corresponding to the annual water releases scheduled for November (Figure 3). However, the bypassed reach may have been impacted by water and sediment inputs from intermediate watersheds, particularly in 2014 , when significant rainfall was observed $(>80 \mathrm{~mm})$ and to a lesser extent in $2015(20 \mathrm{~mm})$.

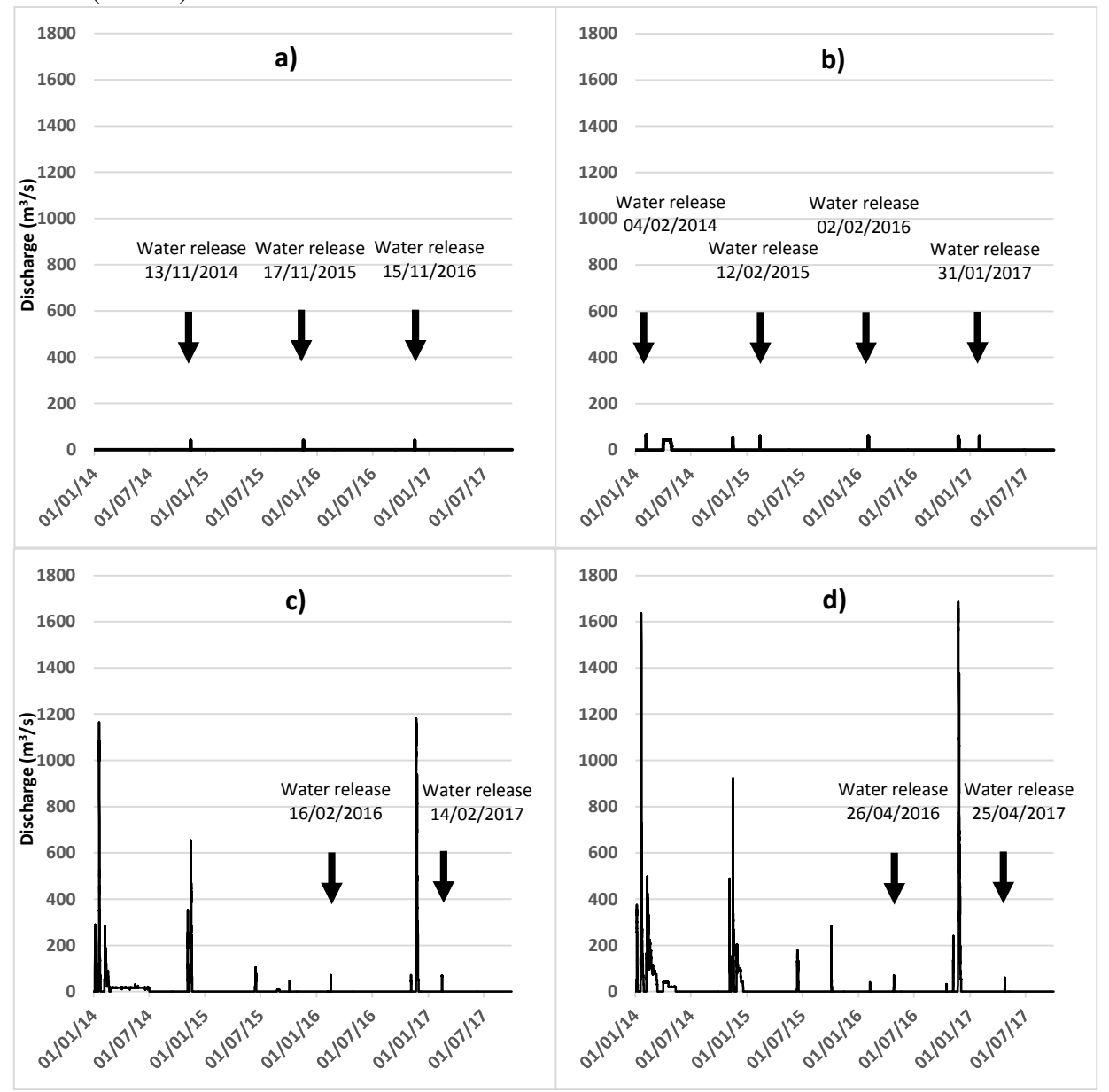

Fig. 3. Hydrographs observed in each reaches for the years 2014-2017, a) Espinasses b) La Saulce c) L'Escale d) Cadarache

At the Saulce reach, 7 spills at the dam were observed over the period, including the 4 planned water releases. In 2014, the release of water was not linked to another spill period 
but significant precipitation occurred (10-20 mm/day) making it difficult to collect data immediately after the water release. Between 2015 and 2016, water releases were the only events observed at the dam. In 2017, precipitation was high post-release and the campaign immediately after it was cancelled. For the Escale and Cadarache reaches, the 2016 water releases occurred in a period of low flows with only one exceptional dam discharge event (lasting one day and of lesser magnitude than the water release) 4 and 2 months before the release, respectively. In November 2017, a week-long flood (approximately 10-year return period) was observed at Escale (peak flow of $1200 \mathrm{~m}^{3} / \mathrm{s} 3$ months prior to the release) and at Cadarache $\left(1700 \mathrm{~m}^{3} / \mathrm{s} 5\right.$-months prior to the release).

\section{Monitoring programme}

To evaluate the efficiency of the water releases, an ambitious monitoring programme spanning at least 3-6 years has been implemented, assessing every major components of the aquatic ecosystem. Rather than seeking to detect statistically significant changes in the various parameters, the monitoring program is aimed at determining whether ecological objectives have been met. Two monitoring objectives are targeted: (1) to directly evaluate the effectiveness of the releases (with respect to reduced benthic clogging) over a period of at least 3 years and (2) to evaluate the overall efficiency of flow mitigation measures on biota over a period of at least 6 years. This contribution provides results of the first phase of the study.

To monitor the efficiency of flow releases, continuous measurements of water depth, SSC, turbidity, conductivity, temperature and dissolved oxygen are conducted during the releases. Clogging (surface and interstitial) is measured 15 days prior to the release, the day after the release and 1-month post-release. All measurements (continuous or local) are taken at 3-4 approximately equidistant stations (Figure 1). Surface clogging is evaluated visually using a semi-quantitative scale designed to describe the level of substrate embeddedness [2]. Interstitial clogging is evaluated using a measure of hydraulic conductivity [3]. Particle size distribution is evaluated using the Malavoi and Souchon [4] method (a semi-quantitative adaptation of the Wentworth scale). Substrate measurements are conducted at 30 points distributed among 5-6 cross-sections per station, placed such that they represent a succession of lotic habitats and correspond to potential fish spawning habitats. In addition, two topographic long profiles (cm precision) are conducted at each station before and after each release to monitor small changes in channel morphology following releases and over several years. This presentation will focus on the morphological aspects.

\section{Initial results}

\subsection{Water release design}

In all of the reaches, the water releases at the dams propagated normally downstream. The rising and falling speeds as well as peak duration are similar between the different stations in each reach.

From a hydrological point of view, the three experimental releases are the only releases produced by the dam during the observation period for the Espinasses reach. For the Saulce reach, water releases are also significant, although three events of the same magnitude were also observed during the period. On the other hand, for the Escale reach, the two releases made during the period were in the middle of spills at the much larger dam, notably the one made in 2017 with a flood peak of nearly $1,200 \mathrm{~m}^{3} / \mathrm{s}$ less than three months before. Water 
releases at Cadarache are also not significant in terms of hydrology over the period. The water releases therefore appear to be significant for the two upstream reaches; however, their importance is a function of the hydrological trend for the two most downstream reaches. For these last two reaches, only one dry year (without spills linked to floods) could make them hydrologically significant.

\subsection{Initial c logging}

The average initial clogging condition varies little from year to year in the Espinasses reach, whereas in principle it is likely to vary more significantly in the other reaches, notably the Escale (braided river reach). Clogging also seems to be more important in the first two reaches that are closed to the upstream large capacitive dam and therefore the most affected by hydrological alteration. The average initial clogging gradually decreases along a downstream gradient to low values such as those observed in the Escale (2017) and Cadarache (2016) reaches. These last two reaches are also less prone to high clogging levels ( 4 and 5). In these downstream reaches, most of the points surveyed are below the clogging level 3 (indicating 50-75\% clogging) whereas on the upstream reaches, on average $1 / 3$ of the points are above this level.

\subsection{Physico-chemistry, grain size and topography}

During the release, water temperature increased by several degrees as the release delivered warmer surface water from the reservoir. Conductivity varied little during the release and dissolved oxygen was unchanged. The effect of the releases on sediment transport (large particles) was insignificant. The minor changes observed in sediment size distribution and channel morphology are likely due the influence of inputs from torrential tributaries (contributing sediments following localised rainfall events). There were also no topographic variations observed. The lack of effects on these parameters was expected, based on the release design.

\subsection{Suspended sediment concentration and transport}

The observed SSC peaks varied significantly among reaches and years. At Espinasses, the SSC peaks vary between 2 and $3 \mathrm{~g} / \mathrm{l}$ during the 3 releases. SSC peaks increased in the downstream reaches. At the Saulce reach, SSC values generally varied between 2 and $4 \mathrm{~g} / \mathrm{l}$. The year 2016 is an exception with a peak of more than $10 \mathrm{~g} / 1$ observed at the downstream end of the reach. Only two releases were carried out at the Escale reach: in 2016, the SSC peak barely exceeded $2 \mathrm{~g} / \mathrm{l}$, whereas in 2017 a release of the same magnitude only generated a peak at $0.7 \mathrm{~g} / \mathrm{l}$. However, the reach of the Escale differs quite clearly from the two previous reaches, as there is no consistent increase in SSC values (in 2016, the peak value is attenuated at station 3 and in 2017 at station 2). The Cadarache reach is characterized by a particularly low SSC content during the 2 releases carried out in 2016 and 2017 with peaks of about 1 and $0.6 \mathrm{~g} / \mathrm{l}$ respectively.

The annual amount of suspended sediment (SS) transported downstream was evaluated by integrating turbidity curves obtained at the last station in each reach. At the Espinasses reach, these quantities do not vary much over the years, even if an upward trend is observed. The amount of SS transported varies between 1850 and 3000 T. At the Saulce reach, the year 2016 is singular with a transport of $11400 \mathrm{~T}$ compared to values between 2850 and $4500 \mathrm{~T}$ in 2014, 2015 and 2017. At the Escale reach, a net decrease in transport is observed from $3100 \mathrm{~T}$ in 2016 to $250 \mathrm{~T}$ in 2017 . The Cadarache reach shows much less transport than the other reaches, with $1300 \mathrm{~T}$ in 2016 and no sediment transport observed at 
the end of the reach in 2017. Most of the water releases result in a sediment output ranging between 2000 and $3000 \mathrm{~T}$, with variations that are sometimes substantial, such as at the Saulce in 2016, or are very localized (Cadarache 2016 and 2017).

\subsection{Effect on clogging}

For all water releases, the comparison of clogging levels at each survey point before and after the releases showed an improvement in the clogging level for $22.5 \%$ of the points, but at the same time a deterioration for $15 \%$ of them (Figure 2). Nearly two thirds of the surveyed points are equally clogged before and after the water releases. The overall trend is still slightly positive, with an improvement in the clogging level for $7.5 \%$ of the points. While the immediate effect of these water releases on clogging seems slightly positive, the longer-term (1 month) trend is neutral. Indeed, the comparison between the initial state and the state 1 month after the water releases indicates that $19 \%$ of the points showed a positive evolution of their clogging level but that the same percentage of points underwent a deterioration. The number of points for which water releases was neutral remains in the order of magnitude of two-thirds.
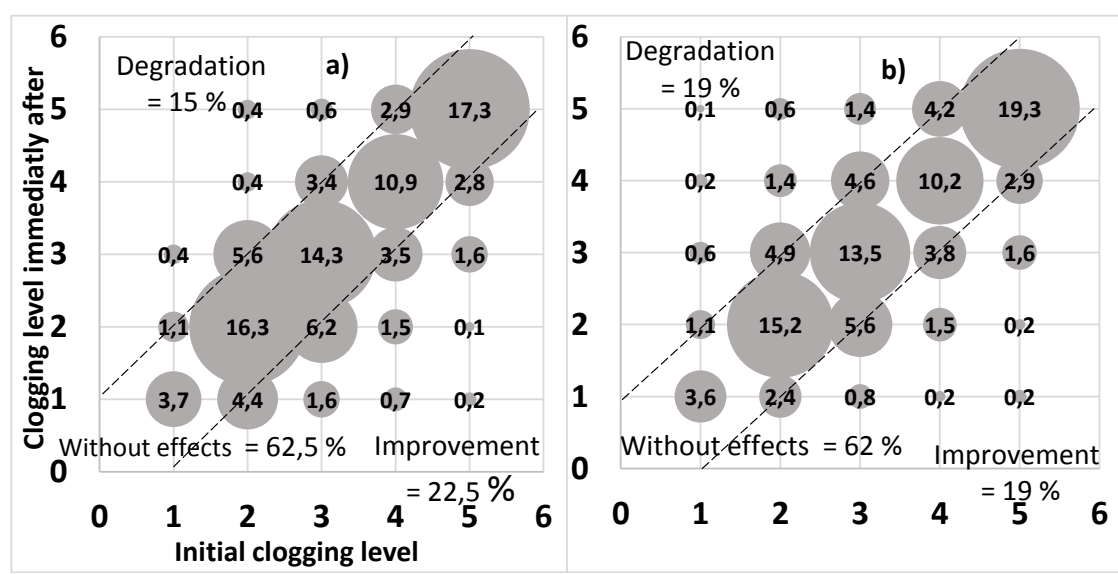

Fig. 4. Evolution of clogging: a) before and immed iately after water releases for all releases and all years together $b$ ) Before and one month after water releases for all releases and all years together

The analysis at the annual scale is delicate as not all releases can be taken into account each year. However, this analysis tends to clearly show a significant success of the releases in 2016 at the Espinasses, Saulce and Cadarache reaches. This was a particular year in which dam overspills were absent at the two upstream reaches or weak for the two downstream reaches. The fine sediments freshly deposited during the year, which could be more easily mobilized, could be taken up again in quantity by the water releases because they were not previously mobilized by floods.

At the scale of each release, there was considerable heterogeneity in the success of water releases. At the Espinasses reach, the 3 releases resulted in very different effects. In 2014 , the release of water visibly led to a deterioration of the river channel clogging ($1.7 \%)$, in 2015 the release of water led to an improvement of the points $(+15.8 \%)$ and in 2016 , even if it led to a less marked improvement $(+8 \%)$, the release remains positive. Other parameters of analysis (degradation, improvement or points without effects) also varied greatly from year to year. At the Saulce in 2015 and 2016, water releases led to gains of $6.7 \%$ and $31.3 \%$ respectively. This last year represents the biggest gain obtained during the tests carried out. The difference between the two years is mainly due to the very 
significant decrease in the number of deteriorating points (from 20 to $1.7 \%$ ) or even the decrease in "no-effects" points (from 65.3 to $53.3 \%$ ) as well as the increase in the points where clogging is reduced (from 36.7 to $33 \%$ ). At the Escale reach, where only two releases were conducted, only one benefited from field campaigns both before and after the release. The results were very unfavourable with a variation of $-21.4 \%$. The proportion of points undergoing deterioration are very high compared to those observed on the other releases (33.3\%). Finally, the results at Cadarache in 2016 and 2017 were also very different, with an improvement of $15.6 \%$ and $4.5 \%$ respectively. The percentage of points in improvement changed little between the two releases (17.8 and 19.3\%); on the contrary, the percentage of points in deterioration $(2.2$ and $14.8 \%)$ and points with no significant effects (80 and 65.9\%) did vary substantially. These results also indicate that in general, when the average clogging index is high, release success is more evident. The lower the index, the greater the chance of negative environmental impacts is.

\subsection{Effect on interstitial clogging}

The evolution of the infiltration ratio was calculated at the station scale before and 1 month after the releases. According to the classes proposed by [3], all stations appear to be "unclogged" prior to the release, with the exception of one station in the Saulce reach in 2014, which is classified as "slightly clogged". The evolution of the percentage of infiltration points changes very little between the initial state and the state after release $(<10 \%$ on average). The percentage of points with infiltration changes both downwards and upwards after releases, but remains unclogged or only slightly clogged. The calculated infiltration velocities also show no significant variation before and after water releases, but only a longitudinal gradient depending on the distance from the Serre-Ponçon dam.

\section{Conclusion}

It has been shown that several of the experimental flow releases were not effective on surfacial clogging inducing a loss of water or effects contrary to those expected, although this was not reflected in the biological results (no adverse effects were observed based on ecological monitoring). Studies show that two parameters must be taken into account to determine a priori the need to carry out releases: the hydrology observed during the year (presence of floods prior to the release) and the initial level of clogging. When there are no floods between two releases, the results are better.

\section{References}

1. J.D. Olden, C.P. Konrad. Are large-scale flow experiments informing the science and management of freshwater ecosystems? Frontiers in Ecology and Environement 12: 176-185. (2014).

2. G. Archambaud, L. Giordano, B. Dumont. Description du substrat minéral et du colmatage. Note technique provisoire. CEMAGREF Aix en Provence. 7p. (2005)

3. Datry, T., Lamouroux, N., Thivin, G., Descloux, S. Baudoin, J.M. Estimation of sediment hydraulic conductivity in river reaches and its potential use to evaluate streambed clogging. River Research and Applications. (In press)

4. Malavoi, J.R., Souchon, Y. Méthodologie de description et quantification des variables morphodynamiques d'un cours d'eau à fond caillouteux. Exemple d'une station sur la Filière (Haute Savoie). Revue de Géographie de Lyon 64: 252-259. (1989) 